\title{
IMAGINÁRIO INFANTIL E PÓS-VERDADE: ENTRELAÇOS MIDIÁTICOS EM PERSPECTIVA DISCURSIVA E POLÍTICA
}

Juliene da Silva Marques ${ }^{1}$

Samantha Dias de Lima²

\section{INTRODUÇÃO}

O imaginário infantil faz-se presente no cotidiano de toda criança. Nesse sentido, diversas possibilidades de sonhos e fantasias são criadas, principalmente se estimuladas. Dessa forma, percebe-se que o faz-de-conta é vivenciado rotineiramente, fazendo com que a criança dialogue com sua realidade e com as representações sociais que faz de seu próprio entorno.

Diante disso, é possível fazer uma reflexão sobre a verdade no contexto infantil. No entanto, é preciso destacar que o conceito de verdade tem sido estudado ao longo da história da humanidade e que, devido às diversas perspectivas, há sempre uma abertura em relação às verdades possíveis. Dessa maneira, observa-se no faz-de-conta infantil uma vontade de verdade, uma criação que possibilita um viver outro que se conecta com o viver do próprio sujeito diante de suas condições de produção.

Assim, para analisar o entrelaço entre o imaginário infantil e a pós-verdade, foram selecionados algumas postagens que surgiram a partir da divulgação do bilhete escolar criado por um estudante de 5 anos da Educação Infantil de São Paulo com o intuito de ficar em casa. Vale mencionar que os pais da criança divulgaram o bilhete em suas Redes Sociais e, a partir de então, diversos memes $^{3}$ e postagens foram criados.

Perante esse contexto, tem-se como problema de pesquisa o seguinte questionamento: Como o imaginário infantil se aproxima da pós-verdade no mundo contemporâneo?

\footnotetext{
1 Doutoranda com fomento da CAPES e Mestra pelo Programa de Pós-Graduação em Ciências da Linguagem da Universidade do Sul de Santa Catarina - UNISUL. Professora do Instituto Federal de Educação, Ciência e Tecnologia do Rio Grande do Sul, Campus Vacaria.

2 Docente do Instituto Federal de Educação, Ciência e Tecnologia do Rio Grande do Sul - Campus Farroupilha. Doutora em Educação (UFRGS-2015). Atualmente em estágio Pós-Doutoral no Programa Pós-Graduação em Educação da Universidade do Vale do Rio dos Sinos sob supervisão da professora Elí T. Henn Fabris.

3 "Imagem, informação ou .ideia que se espalha rapidamente através da internet, correspondendo geralmente à reutilização ou alteração humorística ou satírica de uma imagem". Disponível em: <https://dicionario.priberam.org/meme>. Acesso em: 4 abr. 2019.
} 
Para suscitar a discussão a respeito, pretende-se, como objetivo geral, analisar a relação entre o imaginário infantil e a pós-verdade no atual contexto. Já como objetivos específicos, quer-se selecionar as postagens para análise e examinar as marcas discursivas de deslizamento de sentidos que aproximam a postagem da criança e as postagens dos adultos.

\title{
(PÓS)VERDADE EM PERSPECTIVA: ASPECTOS PEDAGÓGICOS E DISCURSIVOS
}

Diversas pesquisas passam pelo entremeio do imaginário infantil, principalmente fazendo referência à representação da realidade através do simbólico.

\begin{abstract}
O imaginário infantil constitui uma das mais estudadas características das formas específicas de relação das crianças com o mundo. A investigação tem sido dominada pelas correntes teóricas da Psicologia. As perspectivas predominantes são as psicanalíticas e as construtivistas. Para Freud, o imaginário infantil corresponde à expressão do princípio do desejo sobre o princípio da realidade, sendo o jogo simbólico uma expressão do inconsciente, para além da formação da censura. Para Piaget, o jogo simbólico é a expressão do pensamento das crianças, progressivamente eliminado pelo processo de desenvolvimento e construção do pensamento racional. (SARMENTO, 2003, p.52).
\end{abstract}

Já para Bachelard (1998), imaginar é a possibilidade de romper com as imagens primeiras, ou seja, criar outras realidades (im)possíveis, principalmente tendo em vista que, a partir do imaginário, pode-se criar narrativas verossímeis ou inverossímeis, pois não há limites estabelecidos. Entende-se que a criança utiliza o imaginário para viver os mais diversos sonhos e conectar-se às múltiplas vidas e personagens que circulam em seu universo.

Nesse contexto, vale mencionar que tomamos o simbólico, ou faz-de-conta, como a possibilidade de criação, de ir além da realidade imediata e, ao mesmo tempo, suscitar uma conexão com as representações sociais já existentes no contexto da criança. Sendo o desenvolvimento do fazde-conta uma possibilidade de construção de outros sentidos, é importante destacar que o sentido, em uma perspectiva discursiva, faz-se possível porque já há sentido. Segundo Orlandi (2017, p. 16), “[...] alguma coisa fala antes, em outro lugar e independentemente". Em outras palavras, pode-se dizer que nossas construções são possibilitadas pela nossa memória discursiva, que se faz presente em nosso consciente e inconsciente. Assim, a criança cria suas novas narrativas a partir de uma narrativa primária, advindas das percepções do seu cotidiano.

Apesar da conexão com a representação da realidade, Cunha (2007, p. 23) destaca que: 
Às vezes, o faz-de-conta não imita a realidade, mas ao contrário, é um meio de sair dela, um jeito de assumir um novo estado de espírito, como, por exemplo, quando a criança veste uma fantasia de palhaço e vai para o fogão fazer comidinha, ou então, veste a fantasia de fada e vai correr e brincar de pegador. Quando existe representação de uma determinada situação, (especialmente se houver verbalização), a imaginação é desafiada pela busca de soluções para os problemas criados pela vivência dos papéis assumidos. As situações imaginárias estimulam a inteligência e desenvolvem a criatividade.

Observa-se que, mesmo ao romper com o verossímil, a criança busca aspectos de seu conhecimento, a partir de suas condições de produção, assim como qualquer sujeito. Discursivamente, analisam-se as condições de produção em dois aspectos: amplo e estrito. Sendo o primeiro referente ao contexto histórico, político, econômico etc.; e o segundo diz respeito ao contexto imediato, ou seja, as relações familiares, às redes sociais estabelecidas na comunidade, na escola etc. (ORLANDI, 2015, p. 28-29). Dessa forma, observa-se que todo o contexto no qual o sujeito está inserido interfere em seu processo de significação, assim sendo, a escola também propagará seus próprios discursos e modos de funcionamento que interferirão na construção de sentidos que o estudante fará.

Cabe destacar que o sujeito, ao construir sentidos, o faz em relação aos outros coenunciadores - por meio de movimentos de antecipação em que "se confrontam a história do dizer do autor e a história de leituras do leitor" (ORLANDI, 1996, p. 75). Durante o processo enunciativo, o sujeito movimenta os sentidos utilizando os chamados mecanismos de antecipação (ORLANDI, 2015). Ou seja, o sujeito se coloca no lugar do coenunciador, para que, dessa forma, possa tentar construir argumentos que atinjam os sentidos pretendidos. Segundo Orlandi (2015), o sujeito ainda utiliza, inconscientemente, a relação de forças manifestada no discurso, porque o local de sua fala também faz com que os sentidos sejam movimentados de uma ou outra forma. Isto é, não se fala de uma mesma forma perante coenunciadores diferentes, pois as relações de força discursiva também se farão distinta. Assim, o dizer de um professor, de um advogado, de um pai, de um padre, entre outros terão seus próprios funcionamentos, regularidades e efeitos que se farão interferentes na construção de sentidos de seus coenunciadores.

Vale mencionar diante do explicitado que o sujeito não constrói os sentidos de forma individual, pois, além de toda a memória discursiva, presente na sociedade, com os movimentos de antecipação, ele se adequará ao contexto e a seus coenunciadores para tentar produzir um sentido $X$ e não $Y$.

Cunha (2007, p. 23), afirma que, no que se refere ao faz-de-conta, “[...] a criança traduz o mundo dos adultos para a dimensão de suas possibilidades e necessidades, as crianças precisam 
vivenciar suas ideias em nível simbólico, para poderem compreender seu significado na vida real". Dessa forma, o sujeito estabelece sua visão a respeito do funcionamento social e passa a entendê-lo gradativamente conforme se aproxima e se afasta de sua realidade por meio de associações, comparações e projeções.

No que se refere às regras estipuladas no contexto social, ou seja, às condições de produção da criança, Oliveira et al. (2002, p. 55) argumenta que:

\begin{abstract}
A brincadeira simbólica leva à construção pela criança de um mundo ilusório, de situações imaginárias onde objetos são usados como substitutos de outros, conforme a criança os emprega com gestos e falas adequadas. Nessa situação a criança reexamina as regras embutidas nos atos sociais, as regulações culturais que fazem que a mãe seja quem fica em casa enquanto o pai sai para o trabalho em certos grupos sociais, por exemplo. Isso ocorre conforme a criança experimenta vários papéis no brincar e pode verificar as consequências por agir de um ou de outro modo. Com isso internaliza regras de conduta, desenvolvendo o sistema de valores que irá orientar seu comportamento.
\end{abstract}

Nesse contexto, a criança também procura construir a sua verdade, ou o que deseja como verdade. Assim, em seu imaginário, o que é construído entende-se como o verdadeiro, o que ela enxerga como visível no mundo real. É a associação da realidade com a verdade numa representação simbólica desses mesmos elementos.

É importante dizer que esse processo simbólico de construção da verdade faz-se importantíssimo para o desenvolvimento infantil, principalmente tendo em vista que serão essas associações com a realidade que constituirão o sujeito em formação em relação ao seu meio social, político, econômico e cultural. Isto é, o entendimento do mundo também se faz a partir da construção subjetiva da verdade.

Foucault (2004, p. 12, grifo do autor) afirma que "Cada sociedade tem seu regime de verdade, sua 'política geral de verdade': isto é, os tipos de discurso que ela acolhe e faz funcionar como verdadeiros; os mecanismos e as instâncias que permitem distinguir os enunciados verdadeiros dos falsos [...]". Ou seja, não se trata da verdade absoluta, mas sim de enunciados que funcionam como verdades a partir do posicionamento de cada sujeito. De acordo com Pereira (2016, p. 35), “[...] não podemos admitir no campo da Análise do Discurso a hipótese de que há um significado real a ser encontrado, ou um saber a ser atingido", porque, os gestos de interpretação e a produção de sentidos são dependentes das condições de produção, que geram posicionamentos diversos.

Deleuze (2000, p. 15), em sua filosofia política, afirma que: “A significação não fundamenta a verdade, sem tornar ao mesmo tempo o erro possível”, isso também é discutido pela Análise de Discurso, pois algo será julgado verdadeiro ou falso de acordo com a produção de sentidos dos 
sujeitos em sua multiplicidade e também tendo em vista a possibilidade de falha, que é constituinte do discurso. O sentido nunca está dado, pois as pessoas vão atribui-lo de acordo com suas condições de produção, e, desse modo, haverá posicionamentos diferentes no que se refere à verdade, pois ela se adequará à visão do individuo em um determinado contexto, promovendo, assim, falhas, que são, nessa perspectiva, os desentendimentos na construção de sentidos.

Durante o processo de enunciação e produção de sentidos, segundo Charaudeau (2009), não se busca 'a verdade em si', mas sim 'credibilidade', posto que, durante a enunciação, há um jogo discursivo no qual os coenunciadores tentam fazer com que os seus parceiros acreditem no que é exposto, como forma de adesão no que se refere à "verdade" argumentada. Foucault (2003, p. 140) argumenta que "[...] estabelecemos discursos e discutimos, não para chegar à verdade, mas para vencê-la [...]", pois se trata de um jogo de convicções entre múltiplos posicionamentos.

Segundo Henry (1997, p. 51-52), “[...] não há ‘fato’ ou ‘evento’ histórico que não faça sentido, que não peça interpretação, que não reclame que lhe achemos causas e consequências. É nisso que consiste para nós a história, nesse fazer sentido, mesmo que possamos divergir sobre esse sentido em cada caso". Desse modo, a subjetividade da busca pela verdade possibilita uma amplitude da construção de sentidos mediante uma posição assumida. De acordo com Orlandi (2015, p. 35), “[...] o sujeito ao significar, se significa. Por isso, dizemos que a incompletude é a condição da linguagem: nem os sujeitos nem os sentidos, logo, nem o discurso, já estão prontos e acabados”, além disso, para a autora, não há um sentido verdadeiro, há possibilidades de sentido. Dessa forma, considera-se, aqui, que a verdade nunca é completa, pois ela depende da atribuição de sentidos e esta, por sua vez, sempre é suscetível à falha, assim, a verdade também se faz falha, incompleta.

Nesse contexto teórico, já se observa que não há uma verdade absoluta que deve ser procurada, lida, ou encontrada. Assim, as diversas sociedades, ao longo da história, sempre apresentaram perspectivas de verdade, a sua verdade. No entanto, na contemporaneidade, tem-se um novo conceito de verdade que se insere no mundo globalizado: a pós-verdade.

De acordo com o Dicionário Oxford ${ }^{4}$, o termo pós-verdade diz respeito a “[...] aquilo que se relaciona ou que denota circunstâncias nas quais fatos objetivos são menos influentes em moldar a opinião pública do que apelos à emoção e à crença pessoal”. Isto é, no contexto globalizado e midiático que se vive na atualidade, não se busca a verdade em si, ou uma verdade em comum. Buscase validar a sua verdade individual, mesmo que esta seja totalmente contraditória aos fatos que circulam e que são comprovados no cotidiano.

\footnotetext{
${ }^{4}$ Disponível em: <https://en.oxforddictionaries.com/definition/us/post-truth>. Acesso em: 25 nov. 2018.
} 
A qualificação do termo é substancialmente questionável como substrato configurador de nova episteme no cenário das teorias do jornalismo e da comunicação, ao se considerar o próprio sentido original platônico de conhecimento científico válido, e, portanto, legítimo, ou seja, como fonte de verdade científica ou conhecimento verdadeiro, que, contudo, se opõe categoricamente à mera opinião factual, infundada, sem qualquer análise e reflexão meticulosa. (QUADROS, 2018, p. 204)

O pesquisador destaca a fragilidade do termo no que se refere ao aspecto científico, justamente por ser baseado em opinião. Nesse sentido, cada um acredita na verdade que lhe convém, sem atribuir razão a um juiz ou a um especialista em uma determinada área, por exemplo.

Além disso, as Redes Sociais marcam o rompimento de distância e de tempo-espaço do mundo globalizado, assim, constata-se que a pós-verdade é concretizada em perfis bolhas, em que só aparecem as verdades as quais o sujeito compartilha. Bauman e Mauro (2016) definem esse sujeito como solitário interconectado, e descrevem da seguinte forma:

[...] Nós invertemos os resultados porque as próprias obrigações foram invertidas: sem dever de selecionar e decidir [o que é verdade], o cidadão é um espectador, é perfeitamente livre, 'inocente' [grifo do autor], de todos, já que não está vinculado a causas e nem é responsável pelas consequências. (BAUMAN; MAURO, 2016, p. 80).

Santaella (2013, p.115) argumenta que: "Cada usuário desenvolve uma maneira de uso e de apropriação das redes que lhe é própria. Cada um decide o que ver, consumir ou com quem quer conviver. Hábitos e usos funcionam como pistas de silhuetas subjetivas de cada usuário".

Diante disso, vê-se que, na atualidade, a busca pela verdade se reconfigurou. Dessa forma, sente-se a necessidade de fazer uma associação entre os aspectos da pós-verdade e o imaginário infantil.

\section{PERCURSO METODOLÓGICO}

Para a produção deste artigo, foram selecionadas quatro publicações que circularam no contexto midiático fazendo referência à verdade, tanto no contexto infantil, quanto no contexto do mundo adulto.

Para entender o corpus de análise, foi realizada uma pesquisa bibliográfica a fim de fazer as associações teóricas. Desse modo, autores ligados à Educação e à Análise de Discurso foram elencados para embasar o estudo aqui realizado. Vale mencionar que, de acordo com Orlandi (2017, p. 282), a Análise de Discurso é a teoria da linguagem que se direciona ao entendimento da construção 
de sentidos e, portanto, interroga a interpretação de sujeitos de acordo com as suas condições de produção, considerando tanto o contexto particular quanto o social.

No que se refere à natureza, a pesquisa se caracteriza como aplicada, pois busca entender os conceitos ao olhar para a realidade, nesse caso, a partir do contexto das publicações midiáticas. Quanto à abordagem, dá-se no sentido qualitativo, pois, por trabalhar com os sentidos, a Análise de Discurso irá procurar entender as razões pelas quais o sujeito atribui determinado sentido, excluindo outros possíveis, considerando as relações de poder e as posições sociais que implicam o processo da construção da linguagem e, portanto, do discurso. Assim, almeja-se, aqui, descrever e explicar a associação entre o imaginário infantil e a pós-verdade por meio das postagens analisadas.

Com relação ao objetivo, considera-se uma pesquisa descritiva, pois esta é aquela que "[...] observa, registra, analisa e correlaciona fatos ou fenômenos (variáveis) sem manipulá-los”. (CERVO; BERVIAN; SILVA, 2007, p. 60).

Na sequência, serão apresentados os recortes para a análise, a discussão e os resultados.

\section{DISCUSSÃO E RESULTADOS}

No que se refere ao imaginário infantil, a criança aciona o faz-de-conta em diversas atividades. Em muitas brincadeiras, observa-se a presença do imaginário como uma forma de integrar ainda mais os pequenos. Isso fica evidente em jogos e brincadeiras simbólicas que envolvem narrativas, sendo construídos personagens, ambientes e enredos próprios de uma determinada situação.

Como mencionado, a construção de sentidos se dá a partir de sentidos já existentes. Assim, quando a criança passa a frequentar o meio escolar, seu imaginário também passa a englobar os aspectos e as regularidades relacionadas à escola. Considerando este contexto, foi divulgado um bilhete escolar escrito por um menino de 5 anos da Educação Infantil de São Paulo. No bilhete, a criança se coloca no lugar da professora para mandar uma mensagem aos pais, como se vê abaixo: 


\section{Figura 1}

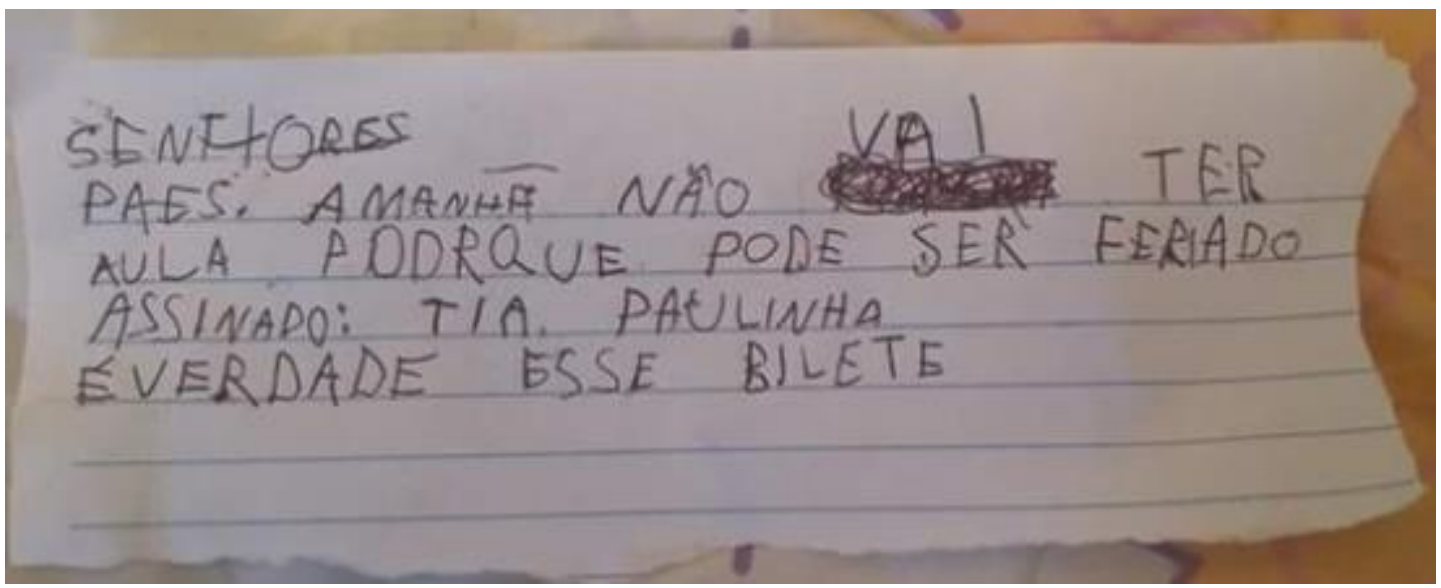

Fonte: Molento (2018).

A criança parte da realidade do contexto escolar para desenvolver a verdade que gostaria de estabelecer. Isto é, como não há aula em determinados feriados, o menino criou essa situação para ficar em casa. Esse fato mostra a construção do imaginário como uma possibilidade de resolução de problemas, como destacou Cunha (2007), anteriormente citado.

Segundo Bujes e Dornelles (2012) quando as crianças são impelidas a fazer escolhas, a tomar decisões e a construir regras, isso não é feito ao acaso, mas considerando um repertório previamente construído segundo as normas sociais que a criança vive, balizado por essa ótica normativa, além do conteúdo em si, observa-se que o bilhete segue a regularidade própria do gênero textual que se insere, contendo saudação, mensagem, assinatura e uma observação. Com esse elemento final, marca-se a vontade de verdade que há no desenvolvimento desse texto. Isto é, a demarcação de uma verdade que se espera concretizar.

Como se observou a partir da fundamentação teórica, a criança, em seu imaginário, reproduz certas regras observadas e aprendidas na sociedade. No caso do bilhete, o menino sabia que a professora tinha autoridade para determinar a conduta dos pais em relação a levá-lo ou não à escola. Ademais, com a produção textual, esperava-se que os pais acreditassem no bilhete, já que era oficial.

Com isso, observa-se o movimento de antecipação executado pelo menino em relação às forças discursivas que são postas em jogo no ato enunciativo. Isto é, a criança sabia que a instituição escolar determina o calendário, os dias letivos, feriados e recessos que serão cumpridos pela escola, sendo os pais submetidos às determinações escolares. Nessa perspectiva, coloca-se em questão quem está falando e para quem está falando, ou seja, as posições de autoridade e de assujeitamento dos 
dizeres. Essas regularidades mostram a perspectiva da criança em relação ao funcionamento do mundo adulto, entendendo que há regras, como dias para estudar e para descansar, bem como reconhece a autoridade de quem manda e quem obedece.

A partir da circulação desse material, diversos outros bilhetes foram produzidos em contextos totalmente diferentes: bebês, crianças, idosos, cachorros, gatos e outros sujeitos foram envolvidos em diversas narrativas. Na sequência, apresentamos duas imagens que refletem essa derivação:

Figura 2

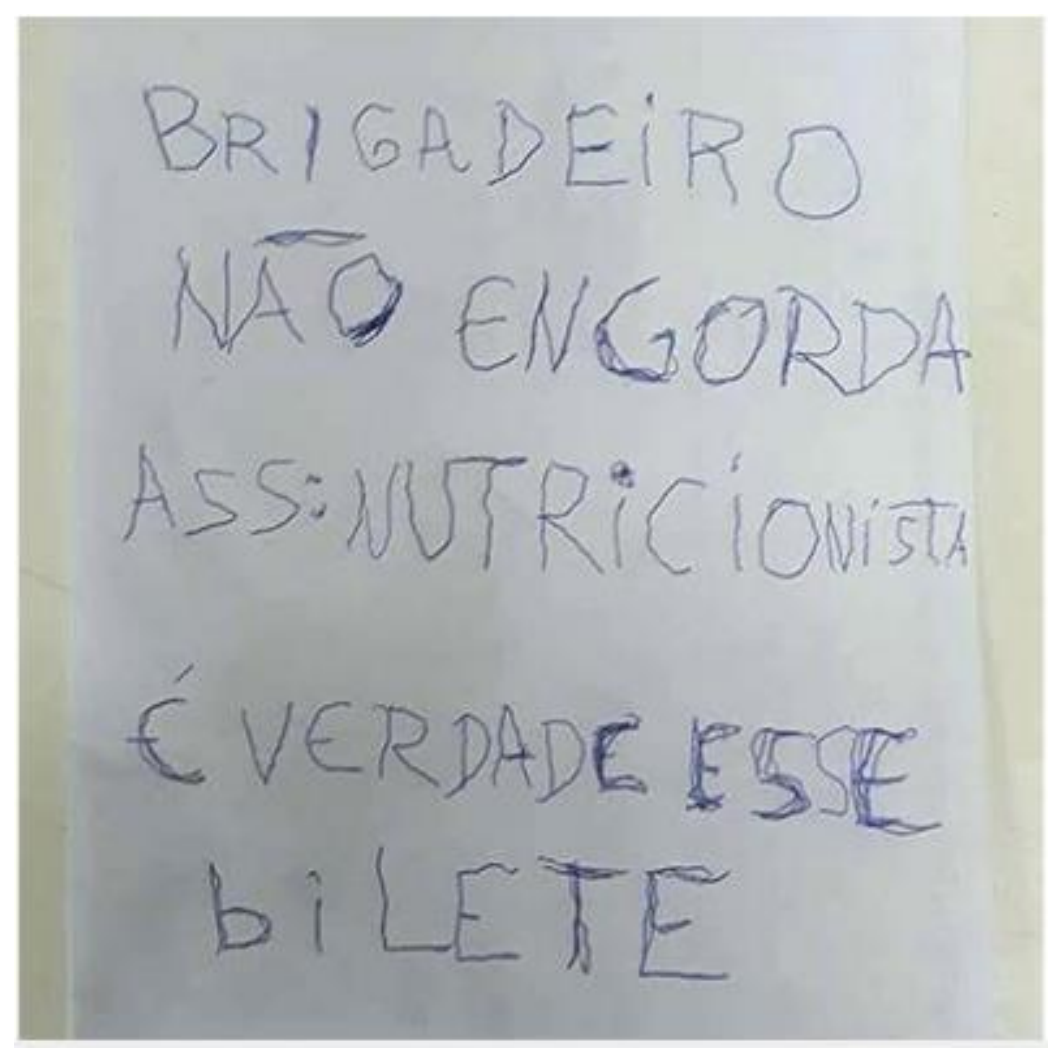

Fonte: Molento (2018). 
Figura 3

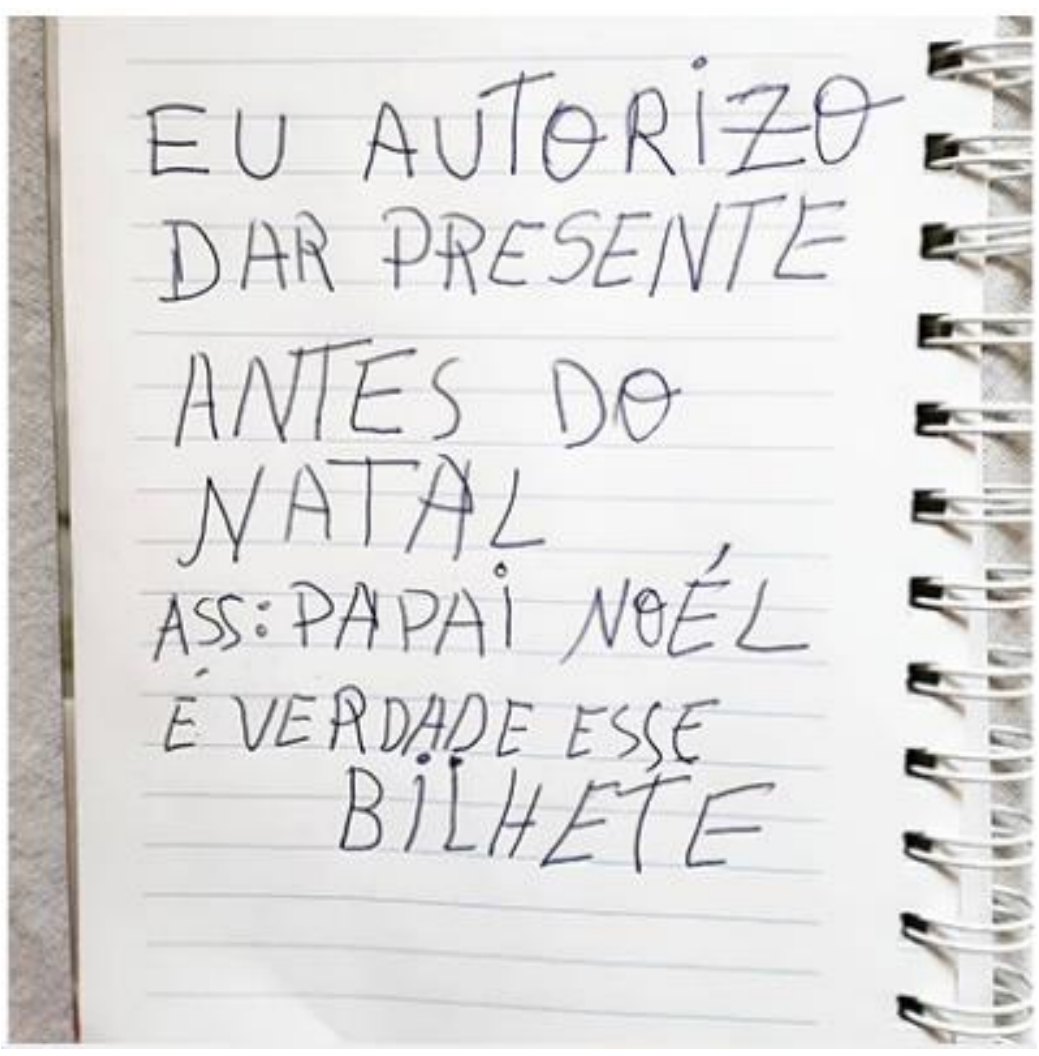

Fonte: Molento (2018).

Nos demais bilhetes publicados, tendo o bilhete da criança como disparador, também se percebeu um desejo de verdade, contudo esse desejo tinha caráter figurado, uma vez que não poderia se dar de fato no cotidiano devido às regras sociais e naturais. Como se observa na figura 2, queriase que o doce brigadeiro não fosse motivo para calorias extras, sendo marcado como verdade esse bilete. Na figura 3, deseja-se como verdade que os presentes de Natal fossem entregues antes da data comemorativa, com a assinatura oficial do Papai Noel.

Esses exemplos ilustram como a publicação de uma produção - originalmente - infantil em um contexto específico derivou-se para diversas outras situações em torno das verdades que se desejam. Verdades que não são absolutas, que não se fazem verdades em si, mas que se pretendem como possíveis verdades.

Diante dessas materialidades, pode-se fazer uma relação com as fake news, tão populares na atualidade. Muitos sites já se utilizavam de notícias falsas como forma de entretenimento para o público. No entanto, no cenário contemporâneo e, principalmente, político e diante das novas possibilidades advindas do meio midiático digital, passaram a circular diversas notícias e dizeres simplesmente inventados, provavelmente com intuito de manipular a construção de sentidos da 
sociedade. Com isso, muitos posicionamentos particulares são assumidos perante algo inventado, compartilhado e que, muitas vezes, permanece como um discurso recorrente na sociedade, mesmo quando a verdade sobre uma mentira é revelada, isso porque, em diferentes contextos, as notícias falsas, fake news, fazem referência a um desejo de verdade, que se quer como verdade, mesmo não o sendo.

Esse deslizamento de sentidos aproxima-se ao que se refere à pós-verdade, tendo em vista que esta não precisa de fatos, apenas de vontade própria. Vale destacar que, com a pós-verdade, estabelece-se uma verdade individual ou coletiva que parte da subjetividade dos sujeitos envolvidos, não sendo, necessariamente, marcada como um desejo, mas, sim, como uma verdade já concretizada. Isto é, mesmo perante inverdades, passa-se a impressão de que o que está sendo propagado é uma verdade factual e absoluta.

No caso das postagens investigadas nesta pesquisa, mostra-se esse desejo de tornar verdade o que não é. Considerando esse contexto, as postagens também possuem envolvimento com as questões políticas, nas quais os desejos pela verdade se fazem efervescentes e, muitas vezes, utópicos.

Figura 4

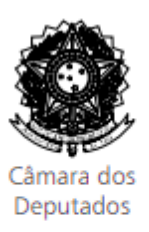

\section{PLANO NACIONAL DE EDUCAÇÃO 2014-2024}

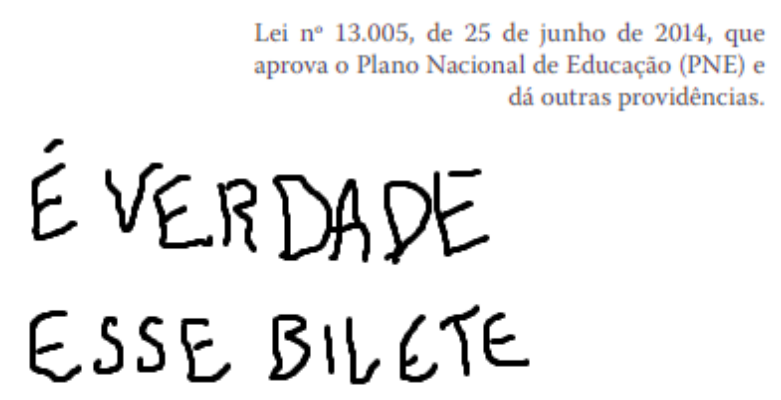

Fonte: Basílio e Daher (2018).

Como se observa na figura 4, o bilhete produzido pela criança acabou sendo aproveitado no contexto político educacional brasileiro, sendo este um dos recortes possíveis de se realizar nesse interim. Quando se faz esse deslizamento, ao mesmo tempo em que se mostra um desejo de verdade, 
evidencia-se que a execução da lei não se faz em todo enquanto uma verdade, o que gera uma crítica importante para o meio educacional e político. Uma vez que, apesar de estipulado em lei, os fatos não comprovam a execução de uma verdade, o que faz com que o texto legislativo funcione, apenas, como uma vontade de verdade, ação está que tem sido recorrente na sociedade brasileira.

\section{CONSIDERAÇÕES FINAIS}

Este artigo procurou traçar uma aproximação entre o imaginário infantil e a pós-verdade. Por meio de publicações de redes sociais, foi possível constatar o deslizamento de sentidos entre uma produção infantil e produções dos contextos paralelos, inclusive do meio político, em destaque na última imagem, de políticas educacionais.

Com a investigação, foi possível observar um desejo de verdade, bem como da construção dessa verdade, tanto no contexto infantil quanto no contexto adulto. Assim como no imaginário infantil, a pós-verdade se faz a partir da subjetividade, dos gostos e das relações pessoais que são projetadas na construção de realidades particulares.

As análises apontam que a busca pela verdade foi sempre um desejo, no entanto, no mundo globalizado, com tempos e valores tão fluídos, a verdade não precisa de fatos para se fazer crer, e essa configuração demarca uma mudança de perspectiva social e política.

Dessa forma, fazem-se apontar algumas reflexões para futuras pesquisas considerando o cenário da Educação Brasileira: O que é verdade ou pós-verdade nesse meio? Existem fatos que comprovam a verdade? Quais opiniões demarcam as verdades que circulam no meio midiático? A busca pela verdade se faz em um único caminho ou é possibilitada por uma resposta apenas? São questões que não se esgotam, e para quais não temos uma verdade como resposta. Assim, o desejo de verdade continua e se faz permanente nas relações sociais, sejam elas infantis e/ou adultas, fazendo com que seja emergente continuarmos atentas e analíticas frente a esta pauta.

Portanto, tendo em vista o contexto contemporâneo de construção, distribuição e manipulação dos sentidos, a busca pela verdade se faz incerta, como em um faz-de-conta infantil, mas em um mundo adulto. 


\section{REFERÊNCIAS}

BACHELARD, G. A Água e os Sonhos: Ensaio sobre a imaginação da matéria. São Paulo: Martins Fontes, 1998.

BASÍLIO, A. L.; DAHER, J. Como os planos de governo se comprometem (ou não) com as metas de educação do país. 2018. Disponível em: <http://www.indicadoreseducacao.org.br/eleicoes-pne/>. Acesso em: 20 nov. 2018.

BAUMAN, Z.; MAURO, E. Babel: Entre a incerteza e a esperança. Rio de Janeiro: Zahar, 2016.

BUJES, M. I. E; DORNELLES, L. V. (orgs.). Educação e infância na era da informação. Porto Alegre: Mediação, 2012.

CERVO, A. L.; BERVIAN, P. A.; SILVA, R. da. Metodologia científica. São Paulo: Pearson Prentice Hall, 2007.

CHARAUDEAU, P. Discurso das mídias. São Paulo: Contexto, 2009.

CUNHA, N. H. S. Brinquedoteca: um mergulho no brincar. 4. ed. São Paulo: Aquariana, 2007.

DELEUZE, G. Lógica do sentido. 4. ed. São Paulo: Perspectiva, 2000.

FOUCAULT, M. A verdade e as formas jurídicas. 3. Ed. Rio de Janeiro: Nau, 2003.

Microfísica do poder. 20. ed. Rio de Janeiro: Graal, 2004.

HENRY, P. A história não existe? In: ORLANDI, E. P. Gestos de leitura: da história no discurso. 2. ed. Campinas: Ed. Unicamp, 1997.

MOLENTO, G. "É verdade esse bilete": veja 10 frases super criativas com o novo meme da internet. 2018. Disponível em: <https://paisefilhos.uol.com.br/crianca/e-verdade-esse-bilete-veja-10-frases-super-criativas-com-o-novo-meme-dainternet/>. Acesso em: 17 nov. 2018.

OLIVEIRA, Z. M. et al. Creches: Crianças, Faz de conta \& cia. 11. ed. Petrópolis, RJ: Vozes, 2002.

ORLANDI, E. P. Interpretação: autoria, leitura e efeitos do trabalho simbólico. Petrópolis: Vozes, 1996.

Análise de discurso: princípios e procedimentos. 12. ed. Campinas: Pontes, 2015.

Eu, Tu, Ele: discurso e real da história. Campinas: Pontes, 2017.

PEREIRA, I. V. Análise discursiva do funcionamento do boato: um gênero (im)possível? 2016. 81 f. Dissertação (Mestrado) - Universidade do Sul de Santa Catarina, Tubarão, 2016. Disponível em: <http://pergamum.unisul.br/pergamum/pdf/112578_Israel.pdf>. Acesso em: 11 out. 2018.

QUADROS, P. Dissimulacro-ressimulação: ensejos da cultura do ódio na era do Brasil pós-verdade. Media \& Jornalismo, v. 18, n. 32, p. 201-218, maio 2018. ISSN 2183-5462. Disponível em: <http://impactumjournals.uc.pt/mj/article/view/5685>. Acesso em: $11 \mathrm{dez} .2018$.

SANTAELLA, L. Comunicação Ubíqua: repercussões na cultura e na educação. São Paulo: Paulus, 2013.

SARMENTO, M. Imaginário e culturas da infância. Cadernos de Educação. Pelotas, n. 21, p. 51-69, jan. 2003. 


\title{
IMAGINÁRIO INFANTIL E PÓS-VERDADE: ENTRELAÇOS MIDIÁTICOS EM PERSPECTIVA DISCURSIVA E POLÍTICA
}

RESUMO: O artigo tem como córpora de análise publicações referentes à verdade e à pós-verdade que circularam no contexto midiático digital. A pesquisa analisa o entrelaço do imaginário da infância com o contexto da pós-verdade contemporânea. A produção original, um bilhete escolar, que se derivou em outras, criada por um estudante de cinco anos. Analisar-se-ão as materialidades em uma perspectiva discursiva de linha francesa com base em um questionamento da interpretação. Os resultados apontam que o imaginário infantil aproximase do conceito de pós-verdade, marcando uma conexão possível em uma linha discursiva entre a infância e o contexto adulto e político do cenário atual.

Palavras-chave: Imaginário Infantil. Pós-verdade. Análise de Discurso.

\section{CHILDREN IMAGINARY AND POST-TRUTH: MEDIATIC INTERLACINGS IN A DISCURSIVE AND POLITICAL PERSPECTIVE}

\begin{abstract}
The article has as a corpus of analysis publications about the truth and the post-truth that circulated in the digital media context. The research analyzes the entanglement of the childhood imaginary with the context of contemporary post-truth. The original production, a school ticket, which was derived in others, created by a student of five years. The materialities will be analyzed in a discursive perspective of French line based on a questioning of the interpretation. The results point out that the child's imagination approaches the concept of post-truth, marking a possible connection in a discursive line between childhood and the adult and political context of the current scenario.
\end{abstract}

Keywords: Imaginary Child. Post truth. Speech analysis.

\section{IMAGINARIO INFANTIL Y POSVERDAD: ENTRELAZOS MEDIÁTICOS EN UNA PERSPECTIVA DISCURSIVA Y POLÍTICA}

El artículo tiene como córpora de análisis publicaciones referentes a la verdad ya la pos-verdad que circularon en el contexto mediático digital. La investigación analiza el entrelazamiento del imaginario de la infancia con el contexto de la pos-verdad contemporánea. La producción original, un boleto escolar, que se derivó en otras, creada por un estudiante de cinco años. Se analizará las materialidades en una perspectiva discursiva de línea francesa sobre la base de un cuestionamiento de la interpretación. Los resultados apuntan que el imaginario infantil se acerca al concepto de post-verdad, marcando una conexión posible en una línea discursiva entre la infancia y el contexto adulto y político del escenario actual.

Palabras clave: Imaginario infantil. Posverdad. Análisis del discurso.

Submetido em Julho de 2019

Aprovado em Novembro de 2019 